\title{
Practice Study of University Sunshine Sports Instructors Work
}

\author{
Deng Jiaping \\ Shanghai Second Polytechnic University \\ djp0331@126.com
}

\begin{abstract}
Analysis of university in carrying out the sunshine sports, how to around college talents training objectives , build for two-level academy "sunshine sports instructors " working mechanism, management system and evaluation mechanisms. And make full use of the school for nearly three years' work practice in sunshine sports instructors ,to explore in depth in how to use the development function of sunshine sports instructors in developing key student of academy sunshine sports and how to improve the improvement ,supervision and guidance of academy sunshine sports instructors.
\end{abstract}

Keywords: University ;Sunshine sports instructors ;Affiliated academy

\section{高校阳光体育指导员工作实践研究}

\author{
邓家平 \\ 上海第二工业大学, 上海, 中国 \\ djp0331@126.com
}

\begin{abstract}
摘要: 简析高校在开展阳光体育运动中, 如 何围绕学校人才培养目标, 建立面向二级学 院的 “阳光体育指导员” 的工作机制、管理 体系和考评机制。并充分运用学校近三年实 施 “阳光体育指导员 “的工作实践, 深入探 究如何发挥阳光体育指导员对学院学生体 育骨干培养的培育功能、如何提升阳光体育 指导员对学院阳光体育运动的指导、督查、 推进作用。
\end{abstract}

关键词：高校; 阳光体育指导员; 下学院

\section{1. 引言}

面对我国高等教育发展的新形势和新 要求, 作为高等教育组成部分的高校体育, 在高校全面推进素质教育、培养身心健康的
具有创新精神和创新能力的高素质复合型 人才中是个薄弱环节, 学生体质和运动能力 是全面发展的关键, 主要制约因素是学生课 外锻炼的内在动力不足, 学校体育的外在激 励不强, 学生体育科学知识欠缺, 学校体育 主管部门长期的持续的支持不够。因此, 高 校体育如何充分发挥体育特有的育人功能, 并把学生课余体育工作作为体育课的延伸, 一直是急待解决的问题。本文就如何在阳光 体育运动中建立 “阳光体育指导员”工作制 度, 发挥体育教师作为阳光体育指导员与二 级学院结对, 深入学院, 指导学院开展学生 群众体育工作进行阶段总结, 旨为改革高校 群体工作进行一定的实践和理论探索, 为高 校学生群体工作开展提供借鉴。 


\section{2. 阳光体育指导员工作的迫切性}

\section{1. 学生 “阳光体育运动”}

根据上海市教委等部门印发的《关于组 织开展上海市学生阳光体育大联赛的通知》 的文件精神, 按照《通知》的有关要求, 结 合本校的实际和特点, 在体育课之外, 把开 展学生 “阳光体育运动” 作为学校体育工作 的突破口, 坚持 “立足校园、面向全体学生” 的组织方针, 学校以 “人人有项目, 班班有 活动, 学校创特色”为目标, 每年制定校“阳 光体育大联赛” 组织实施方案。

在体育部内以体育教师自愿报名, 体育 部选拔考核的形式, 为学校内九个二级学院 派遣了 “阳光体育指导员”, 在学校 “阳 光体育大联赛” 组织实施方案的基础上, 分 别指导学院制订学院阳光体育运动促进计 划, 二级学院学年和学期开展体育活动和体 育竞赛的计划。并负责该项工作的计划实 施, 平时注重对学院体育骨干的培训, 内容 包括工作职责、群体工作方法、小型体育竞 赛编排与组织等。

\section{2. 指导思想与目标}

阳光体育指导员在开展阳光体育运动 时进一步积极组织和引导全体学生做实两 个 “ 1 ” : 即帮助学生树立 “健康第一” 的 生活观念和坚持每天锻炼的良好习惯, 以群 众性体育竞赛活动为平台, 建立校园体育活 动的长效机制, 实现 “人人有项目、班班有 团队、时时有比赛” 的思想与目标。同时落 实每天 “锻炼 1 小时” 以课内外一体化的形 式增设学生喜爱、锻炼价值大、内涵丰富的 课程和课外活动内容和形式, 保证体育课、 晨练、课外活动、各类竞赛的质量和数量。

\section{3. 建立 “阳光体育指导员” 制度, 指导阳光 体育运动的开展}

3. 1. “阳光体育指导员” 制度就是实行体育 教师与二级学院结对, 担任二级学院的 “阳 光体育指导员”, 对学院阳光体育运动的开 展进行指导。该制度的设立是为了积极引导 学生参加体育锻炼, 使他们逐步养成科学健 身的习惯, 提高学生健康水平, 鼓励学生参 与各类体育竞赛, 并指导学院的各项体育活 动、赛事, 推进学院学生阳光体育运动开展。
3. 2. 阳光体育指导员的主要工作一是骨干 培养。“阳光体育指导员” 在落实所指导的 学院后, 充分利用体育课外活动、群体竞赛 等活动平台, 为学院阳光体育活动培养体育 干部和群体活动骨干, 建立院、系、班级群 体活动组织网络, 扎实有效的推进学院群体 工作开展。

二是指导督查。“阳光体育指导员” 要 经常与学院主管学生工作负责人、学生体育 部长、体育骨干进行沟通, 指导学院制定开 展群体活动的计划, 解决在开展群体活动中 存在的问题, 加强群体活动计划实施的过程 监控, 切实推进学院阳光体育运动开展。

三是总结提高。“阳光体育指导员” 在 开展工作中, 要注重总结经验, 发现工作中 存在的问题, 给予及时纠正; 对活动中表现 突出的先进集体和个人的事迹要及时上报, 对所有组织参加过的活动、比赛的图文资 料, 按要求进行总结汇总, 并将其作为年终 评选的依据, 通过总结, 提高阳光体育运动 的成效, 让阳光体育惠及每一位学生。

为加强 “阳光体育指导员” 工作的过程 化管理, 使阳光体育指导员与二级学院结对 指导工作更具实效性，体育部还制定了《阳 光体育指导员工作手册》。阳光体育指导员 制度是我校积极推进阳光体育运动的一个 重要举措, 起到了 “上情下达、下情上传” 纽带作用, 起到一个专家的指导作用, 起到 一个指导与督查的作用。

\section{4. 阳光体育指导员工作要求}

4. 1. 结合学生思想政治工作, 运用体育竞赛 活动的形式, 展示良好的精神风貌, 使学生 意志品质得到锻炼提高, 同时注重发展学生 的组织能力。

\section{2. 结合贯彻落实《学校体育工作条例》,} 提升学生健康体质水平, 深化 “体教结合” 改革发展。

4. 3. 结合学校课程教学, 社会实践和成长记 录评价, 推进面向全体学生的素质教育。

4. 4. 结合学院群体工作, 充分发挥体育指导 员的专家作用, 规范适时的组织参与学校组 织的各项体育竞赛活动。 
4. 5. 结合学院群体工作, 辅导学生体育锻 炼, 开展学院班级层面学生的体育活动和竞 赛活动。

\section{5. 阳光体育指导员的管理}

\section{1. 阳光体育指导员的管理}

5.1.1阳光体育指导员的工作由 1 名体育部 副主任负责, 由体育部群体工作指导小组负 责管理。每一年度体育部面向体育教师选聘 “阳光体育指导员”, 体育部群体组负责安 排阳光体育指导员所联系的学院, 负责该项 工作的计划和实施步骤, 期末进行工作总 结、材料汇总和等级评比。学院分管该项工 作的为学院学生工作负责人, 学院安排 1 名 辅导员担任联络员, 根据阳光体育指导员所 开展的工作情况, 对对其进行考核评分。

5. 1.2. 群体工作指导小组加强与阳光体育 指导员和学院的联系, 经常了解他们的工作 开展情况, 创造必要的条件, 协调、支持和 帮助他们做好阳光体育指导员的工作。

5. 1. 3. 群体工作指导小组同时经常的与学 院保持交流, 了解学院的需求, 以便督促阳 光体育指导员开展工作。

\section{6. 阳光体育指导员的考评}

\section{1. 制定阳光体育指导员考核指标}

6. 1. 1. 考核分为三级指标: 学期考评采用 100 分制, 制定计划 20 分、组织机构 10 分、 活动开展40分、竞赛获奖10分、工作总结 20 分五个方面以不同的分值进行考评。

6. 1. 2. 在二级指标的基础上进一步细化考 评指标, 期末通过多方面的考评, 能较全面 的反映体育指导员下学院的工作实绩及阳 光体育运动促进计划完成情况。

\section{2. 阳光体育指导员考评等级: (共分三级)}

6. 2. 1. 体育指导员须按照工作要求, 深入各 学院认真踏实的开展工作, 考评工作每学期 期未进行一次, 根据上交的相关文件材料及 学院各方面的了解反馈情况等进行评比。

6.2.2. 考评检查学院建立推进阳光体育运 动的组织机构 (学院阳光体育领导小组, 下 设竞赛组、群体活动组、宣传组、办公室, 学院所属各班级阳光体育联络员）
6.2.3. 考核方法等级分为一级、二级、三级, 比例为 $3: 3: 4$, 体育部对阳光体育指导员 工作给予肯定并进行奖励。

\section{7. 结束语}

7. 1. 体育部所选派的阳光体育指导员应具 有较强的体育专业背景, 在指导学院开展阳 光体育运动中起到一个核心指导作用。

7.2. 阳光体育指导员应具有开拓创新能力, 在保证学校特色的前提下, 开拓学生喜爱、 锻炼价值大, 内涵丰富、形式新颖的活动内 容和形式, 逐步形成学院阳光体育特色。

7. 3. 阳光体育指导员在工作中应充分发挥 学院学生会、学生体育社团中学生体育骨干 的积极作用, 注重组织发动、由点带面, 形 成层次丰富、形式多样的组织和活动形式。

7. 4. 逐步建立和完善阳光体育指导员对学 生阳光体育运动指导、监督、评价机制, 使 计划制定有指导、活动过程有监督, 评估检 查有指标, 加大表彰力度, 对表现突出的集 体和个人进行奖励。

\section{References}

[1] Liu Hai-yuan, Yang Guoying, Exploration of several issues about developing the Sunny Sports Movement [J].Journal of Physical Education, 2007 (14) : 10-14.

[2] Feng Weirui, XU Lei, An Analysis of "the Sunshine Sports Program” and Research of the Tactics of Its Execution in Colleges and Universities[J]. Journal of Capital Institute of Physical Education.2008(20):13-16.

[3] Cong Hongyan1,Li Xiaowei, A Research on the Value of Sunshine Sports and Sustainable Development[J]. Journal of Beijing Sport University.2010(33):87-90

[4] Li Shengmin, Wang Bo, The Construction of the Sunny Sports Evaluation Index System of Higher Education Institutes[J].Journal of Beijing Sport University, 2011 (34) : 85-88. 